\title{
Sludge Production Characteristics of Sedimentation · Dissolved Air Flotation (SeDAF) Process for Enhanced Phosphorus Removal
}

\author{
Yeoju Jang ${ }^{1 \oplus} \cdot$ Jinhong Jung $^{2 \oplus} \cdot$ Hyangyoun Chang $^{1 \oplus} \cdot$ Nari Park $^{1 \oplus} \cdot$ Miratul Maghfiroh $^{1 \oplus}$. $^{\circ}$ \\ Weonjae $\mathrm{Kim}^{2,+\odot}$ \\ 'University of Science and Technology (UST, KICT School), Civil \& Environmental Engineering \\ ${ }^{2}$ Korea Institute of Civil Engineering and Building Technology (KICT), Department of Land, Water and Environment Research, \\ Environmental Resource Research Center
}

(Received August 18, 2020; Revised October 21, 2020; Accepted November 5, 2020)

Objectives: In order to prevent eutrophication and algal blooms, Ministry of Environment in Korea reinforced the effluent standards of wastewater treatment facilities. As a result, many advanced wastewater treatment processes have been implemented nationwide. Current conventional treatment systems have usually been facing high operational costs and large sludge production problems. Therefore, it is essential to develop more economic and efficient process to cope with these issues.

Methods: The sedimentation and dissolved air flotation (SeDAF) process has been developed, that integrates sedimentation and dissolved air flotation. Several simulation experiments were carried out to verify and optimize the operation conditions of the SeDAF process. Removal efficiencies of each water quality item and sludge mass balance were analyzed intensively in the SeDAF process using the modified jar-test.

Results and Discussion: Removal efficiencies of the SeDAF process were higher and more stable than those of sedimentation process. Several 'sludge production/coagulant dosage' ratios were analyzed and the representative value of $4 \mathrm{mg} \cdot \mathrm{L}^{-1}$ as $\mathrm{SS} / \mathrm{mg} \cdot \mathrm{L}^{-1}$ as $\mathrm{Al}_{2} \mathrm{O}_{3}$ was obtained in the SeDAF process. Fractions of suspended solids (SS) and total phosphorus (T-P) in sludge were measured; the ratios of flotation sludge to sedimentation sludge and fractions of flotation sludge in total sludge had their typical convergence ranges for the conditions of optimal coagulant dosage.

Conclusions: The ratios or fractions of SS and T-P in sludge could be applied as the evaluation indicators of the SeDAF process. The reduction of coagulant dosage could be corresponded directly to the reduction of sludge production.

Keywords: Sedimentation·Dissolved Air Flotation (SeDAF), Sludge Production Characteristics, Phosphorus · Suspended Solid Removal, Enhanced Phosphorus Removal, Wastewater Treatment

The Korean text of this paper can be translated into multiple languages on the website of http://jksee.or.kr through Google Translator. 


\title{
연구논문
}

\section{인 고도처리를 위한 일체형 침전부상공정(SeDAF)의 슬러지 발생특성}

\author{
장여주 $^{1 \odot} \cdot$ 정진홍 $^{2 \oplus} \cdot$ 장향연 $^{1 \odot} \cdot$ 박나리 $^{1 \oplus} \cdot$ 미라툴 $^{\text {매크피로 }}{ }^{1} \cdot$ 김원재 $^{2+\oplus}$ \\ '과학기술연합대학원대학교 건설환경공학 \\ 2한국건설기술연구원 국토보전연구본부 환경자원재생연구센터
}

목적 : 공공수역의 부영양화를 방지하기 위하여 환경부에서는 공공하수처리시설의 방류수 수질기준을 강화한 결과, 국내 하수처리시설에는 다양한 인 고도처리공정이 도입되었다. 기존의 인 고도처리시스템은 일반적으로 과도한 약 품비 및 슬러지 발생 등의 문제를 안고 있기 때문에 새로운 공정의 개발이 필수적이다.

방법: 본 연구에서는 침전과 부상분리를 통합한 일체형 침전부상공정(SeDAF)을 개발하고, 해당 공정의 운전조건 을 최적화하기 위하여 여러 모의실험을 수행하였다. 수정된 Jar-test 기법을 사용하여 SeDAF 공정에서의 수질 변화 및 슬러지 발생특성을 집중적으로 분석하였다.

결과 및 토의: 전 수질항목에서 침전공정 대비 침전부상공정의 제거효율이 우수하고 안정적인 것으로 나타났다. $\mathrm{SeDAF}$ 공정에서는 응집제 주입농도의 증가에 따라 슬러지 발생량이 $4 \mathrm{mg} \cdot \mathrm{L}^{-1}$ as $\mathrm{SS} / \mathrm{mg} \cdot \mathrm{L}^{-1}$ as $\mathrm{Al}_{2} \mathrm{O}_{3}$ 씩 비례하여 증가하는 것으로 나타났다. 최적처리조건(최적 응집제 주입조건)에서 부상슬러지 및 침전슬러지 내 고형물질 (suspended solids, SS) 및 총인(total phosphorus, T-P)의 부하비율(ratio)과 총 슬러지 대비 부상슬러지 내 SS 및 T-P 의 부하분율(fraction)은 일정한 범위로 수렴하는 것으로 나타났다.

결론: 슬러지 내 부하비율(ratio) 및 부하분율(fraction) 인자를 모니터링함으로써 일체형 침전부상공정(SeDAF) 운 전조건의 적정성을 판단할 수 있는 것으로 나타났으며, 응집제 주입농도의 저감이 슬러지 발생량의 감소로 직결됨 을 확인하였다.

주제어: 침전부상공정(SeDAF), 슬러지 발생 특성, 인·고형물 제거, 인 고도처리, 하수처리

\section{1. 서론}

하수처리시설에서 인 고도처리공정으로 유입되는 원수는 고형물(suspended solids; SS) 농도가 높으며 부하변동이 큰 특징이 있어, 인 고도처리시설은 이러한 유입원수의 부하변 동에 효율적으로 대응가능하며 처리수질을 안정적으로 유 지할 수 있어야 한다. ${ }^{1-3)}$ 기존 침전공정의 경우 고농도 원수 유입 시 운전 및 유지관리 측면에서 용이하며 부하변동에 강한 측면이 있지만, 2 차 이상 침전공정을 경유한 유입원수 는 탁도 물질과 인이 이미 상당부분 처리된 이후이기 때문 에 추가적인 제거를 위해서는 응집제를 과다하게 주입한 스 윕플록(sweep floc)의 형태로 처리하므로 운영비용의 증가 와 과량의 슬러지 발생 등의 문제가 있다. ${ }^{4-6)}$ 부상분리공정 (dissolved air flotation; DAF)의 경우 응집제를 소량 주입한 핀플록(pin floc)의 형태로 부상 및 제거가 이루어지며 발생 한 슬러지의 함수율이 낮고 탈수성이 우수한 장점이 있으
나, 고탁수 원수 유입 시의 효율저하 및 처리수질의 안정성 확보에 문제가 있다. 국내에서 부상분리공정은 2012년 기준 으로 표면여과공정(총 330 개소 중 91 개소)에 이어 두 번째 (총 330 개소 중 86 개소)로 많이 도입된 인 고도처리시설에 해당한다. ${ }^{7-10)}$ 기존의 인 고도처리는 단일공정이 적용되고 있으며, 유입유량 및 수질 등의 조건이 안정적일 때에는 문 제가 없으나 수질 변동이 큰 경우 빠른 대처가 어려우며 과 다한 약품의 주입으로 슬러지가 과다 생성되는 등 경제성이 저하되는 측면이 있다. 이에 다양한 원수 조건에 적용이 가 능하며, 슬러지 및 약품 저감을 통해 경제성이 향상된 인 고 도처리공정의 개발이 필요한 실정이다. ${ }^{10-12)}$

본 연구에서는 기존의 인 고도처리공정의 단점을 보완한 새로운 공정으로 일체형 침전부상공정(Sedimentation·DAF process; SeDAF process)을 개발하였다. 해당 공정은 침전 + 부상분리(DAF)를 연계한 신공정으로, 한 반응조에서 침전 공정과 부상공정이 상호 보완적으로 운영되도록 융복합적 


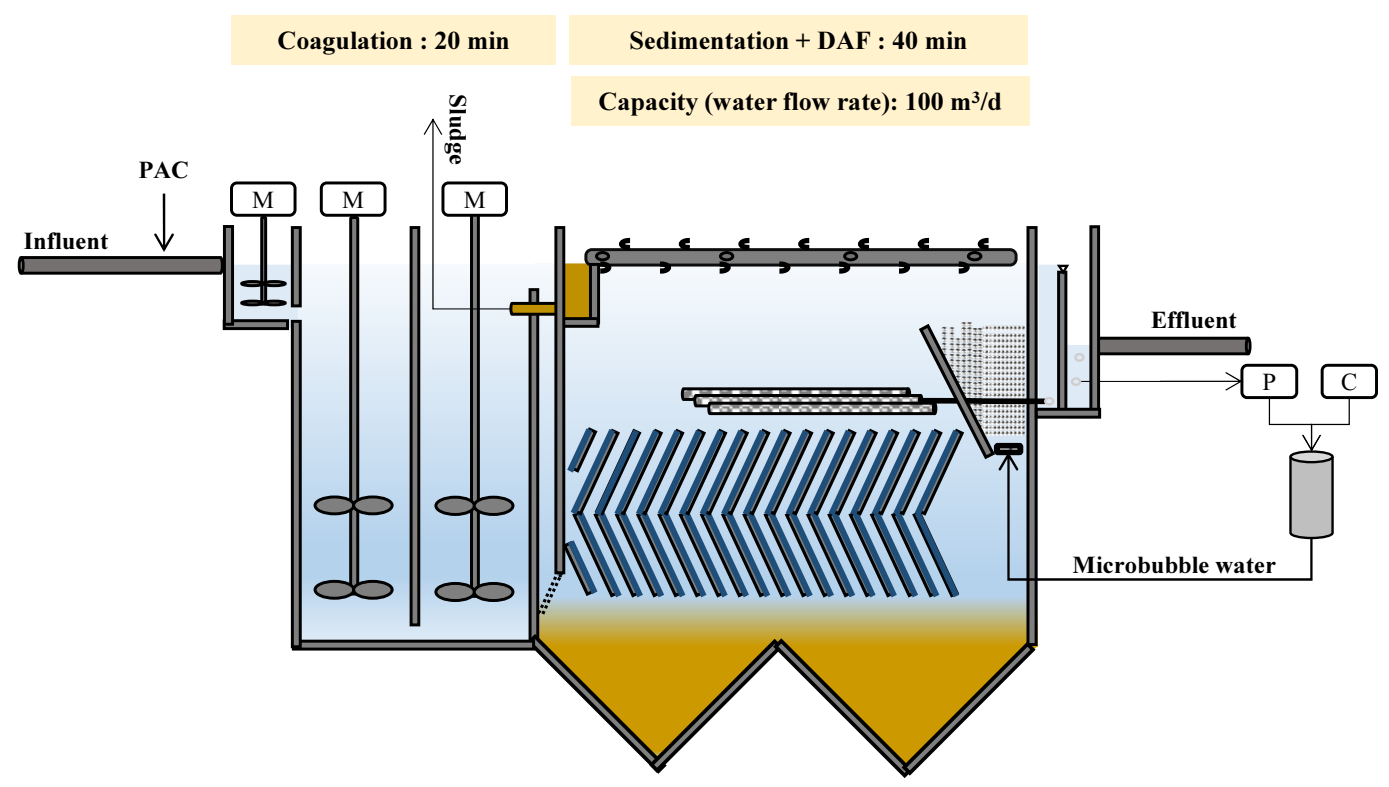

Fig. 1. Conceptual diagram of SeDAF plant.

으로 구성된 공정이다. ${ }^{13-16)}$ 침전공정과 부상공정의 각 단위 공정을 연계적·효율적으로 운영하기 위하여 실험실 규모 연구를 수행하였고, 수질적 측면과 슬러지 발생특성 측면을 구분하여 분석을 수행하였으며, 최적 조건에 따른 특성을 도출하였다.

\section{2. 실험방법 및 재료}

\section{1. 일체형 침전부상공정(SeDAF)}

일체형 침전부상공정(SeDAF)의 개념도는 Fig. 1과 같다. 반응조는 혼화, 응집, 침전부상조로 구성되어 있으며, 수류 의 흐름은 '혼화조-응집조- 침전부상조-최종처리수조'의 순서로 이루어진다. 침전부상조는 한 반응조 내에서 격벽 없이 구성되어 있고, 하부와 상부는 각각 침전부 및 부상부 에 해당하며, 수류의 흐름은 침전공정 완료 후 부상분리공 정의 순서로 순차적으로 이루어진다. 응집 이후 수류의 흐 름은 침전부 하단에서 평행하게 흐르며, 조의 말단부에 다 다라서 미세기포수(가압수)가 유입되어 수직으로 상승하는 흐름을 나타낸다. 부상분리공정의 흐름은 침전부와 반대 방 향으로 상부에서 평행하게 흐르게 된다. 응집완료 이후 형 성된 플록은 원수의 성상에 따라 밀도가 높은 침강성 플록 과 가벼운 부상성 플록이 혼재하는 상태가 된다. 이 때 침전 부상공정의 운전을 통해서 상호 보완적인 플록의 제거가 가 능하게 된다. 최종처리수는 중간부의 최종처리수 유공관을 통하여 별도의 동력 사용 없이 유출된다.

\subsection{Jar-test 기반 침전부상공정 모의실험}

\subsubsection{Jar-test 기반 침전부상공정 모의실험 개요}

인 고도처리를 위한 일체형 침전부상공정의 실험실 검증을
위해 Jar-test 기반의 모의실험을 수행하였다. 해당 모의실험의 전체 공정은 Fig. 2(a)와 같다. 응집제로는 Poly Aluminium Chloride ( $\mathrm{PAC}, \mathrm{Al}_{2} \mathrm{O}_{3} 10 \%$, 염기도 $40 \%$ )을 사용하였다. 실 험조건은 $2 \mathrm{~L} \mathrm{Jar}$ 에 원수를 충전하여 혼화 0.5 분 $(200 \mathrm{rpm})$, 1 차 교반 10 분 $(85 \mathrm{rpm}), 2$ 차 교반 10 분 $(45 \mathrm{rpm})$ 순서로 진행 하였고, 교반완료 시점으로부터 20 분간 정치하여 침전공정 모의실험을 수행하였다. 부상공정은 침전공정 완료실험수 $1 \mathrm{~L}$ 에 미세기포수 $150 \mathrm{~mL}$ (총 유량의 $15 \%$ )를 하부에 주입 하였으며, 주입 후 5 분이 경과한 시점에 최종처리수를 채수 하였다. 미세기포수는 Platypus ${ }^{\circledR}$ DAF Jar-tester 실험장치를 이용하여 제조 및 주입하였으며, 증류수를 사용하여 실험한 후 희석배수를 반영하여 분석결과를 교정하였다. 실험장치 는 탱크 내부에 물과 공기를 접촉시킨 후 $4-5 \mathrm{~kg} / \mathrm{cm}^{2}$ 의 압 력을 가하여 과포화수를 생성한 뒤 대기압 상태로 분출시켜 미세기포수를 제조하는 방식을 채택하고 있다. 부상공정 완 료시점은 $30 \mu \mathrm{m}$ 이상의 미세기포가 전부 부상하는 데 소요 되는 시간(1 L Jar의 수심인 $10 \mathrm{~cm}$ 기준)을 Stokes' law로부 터 도출하였으며, $50 \%$ 의 안전율을 추가로 고려하여 총 시 간(5분)을 설정하였다. 공정의 효과를 확인하기 위하여 침 전공정 및 부상공정 완료 후 처리수와 슬러지를 각각 채수 및 채취하였다(Fig. 2(b)). 슬러지 발생특성을 파악하기 위해 채취된 슬러지 내 고형물질(suspended solids, SS) 및 총인 (total phosphorus, T-P)의 물질수지 분석을 수행하였다.

Jar-test 원수는 고도처리 유입수인 2차침전지 유출수를 대 상으로 하였으며, 실험의 제어조건은 원수 T-P 농도를 기준 으로 설정하였다. 원수 범위는 기존 문헌에서 분석된 비고 도처리시설 방류수 및 인 고도처리공정 유입수의 일반적 T-P 농도인 $0.03-3.0 \mathrm{mg} / \mathrm{L}$ 범위에 해당하도록 하였으며, 해 당 범위의 실험을 진행하기 위하여 원수의 농도 조절이 필 


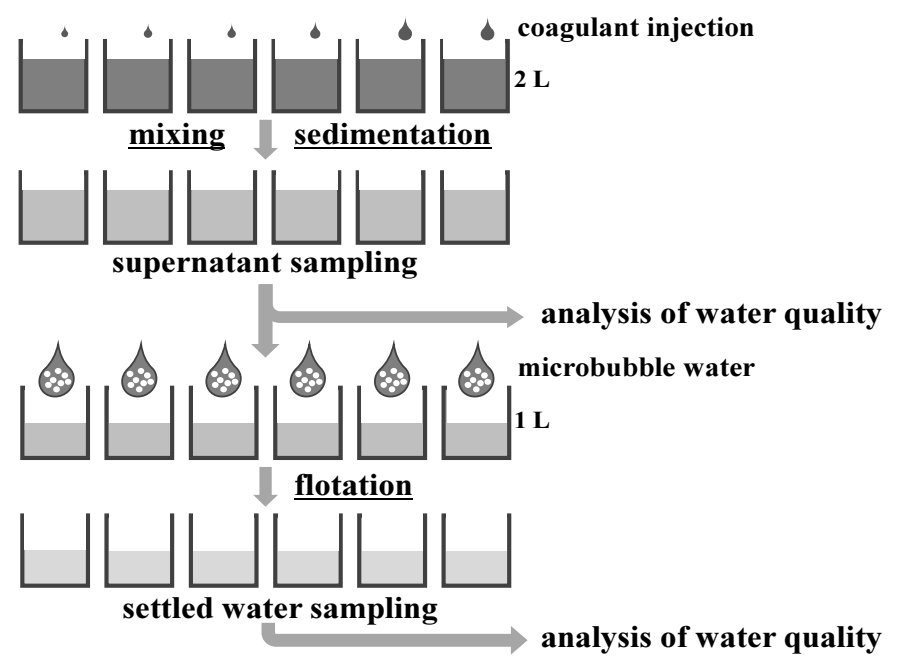

(a)

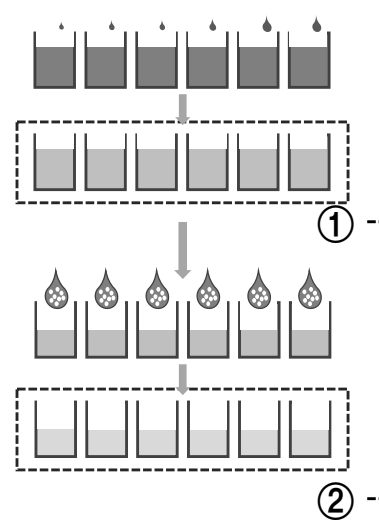

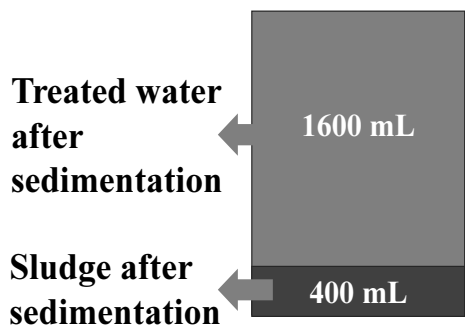

(1) Water and sludge analysis after sedimentation

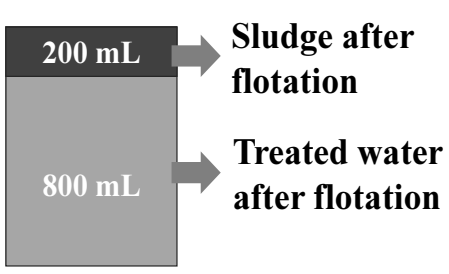

(2) Water and sludge analysis after flotation

(b)

Fig. 2. Sedimentation and flotation Jar-test: (a) experimental procedure and (b) analysis procedure of sludge mass balance.

Table 1. Raw water qualities of lab-scale tests.

\begin{tabular}{cc} 
Items & Range (average) \\
$\mathrm{T}-\mathrm{P}(\mathrm{mg} / \mathrm{L})$ & $0.3-3.0(1.49)$ \\
\hline $\mathrm{PO}_{4}-\mathrm{P}(\mathrm{mg} / \mathrm{L})$ & $0.03-0.66(0.164)$ \\
\hline Turbidity (NTU) & $2.1-37.8(13.28)$ \\
\hline
\end{tabular}

요할 경우에는 2 차침전지 전단계인 생물학적 처리공정에서 유출되는 슬러지를 주입하여 조절하였다. 원수 성상은 Table 1에 정리한 바와 같다.

\subsection{2. 최적처리조건}

결과 분석에는 최적처리조건(Optimal treatment condition) 의 개념을 도입하였다. 이는 1) 방류수 수질기준 항목 중 T-P $0.2 \mathrm{mg} / \mathrm{L}$ 및 SS $10 \mathrm{mg} / \mathrm{L}$ 의 방류수질을 만족한 조건에 서, 2) 응집제를 최소로 주입한 조건에 해당한다(Fig.3). 현 행 공공하수처리시설의 가장 엄격한 방류수 수질기준(I 지 역)에서는 T-P $0.2 \mathrm{mg} / \mathrm{L}, \mathrm{SS} 10 \mathrm{mg} / \mathrm{L}$ 이하로 배출하도록 규 정하고 있다. ${ }^{17)}$ 처리효율이 증가할수록(처리수질이 낮아질 수록) 응집제 주입량과 슬러지 발생량이 모두 증가하므로 ${ }^{18)}$,

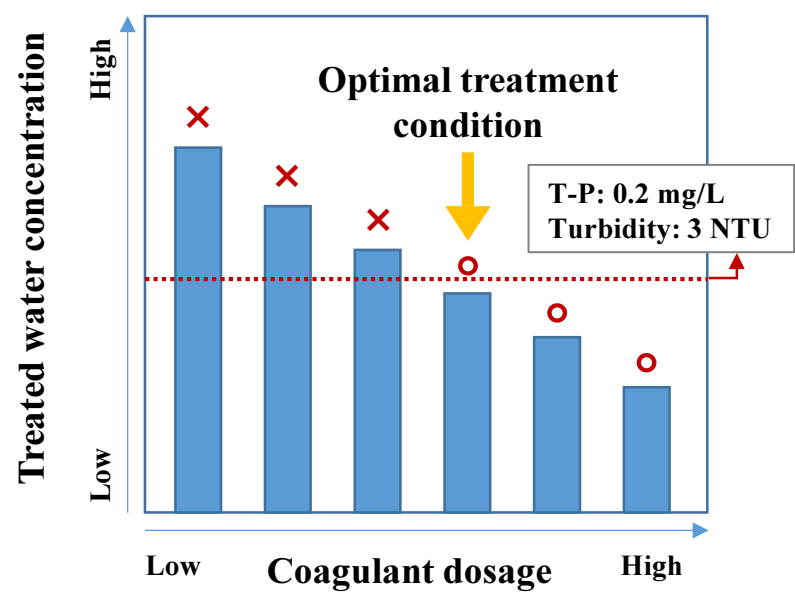

Fig. 3. Concept of optimal treatment condition.

하수처리장에서는 각 지역별 수질기준에 맞추어 처리수질 을 설정하여 운영한다. 따라서 본 연구에서도 방류수 수질 기준을 기준으로 한 최적처리조건을 도입하였으며, 가장 처 리 수질기준이 높은 I지역의 T-P $0.2 \mathrm{mg} / \mathrm{L}$ 및 SS $10 \mathrm{mg} / \mathrm{L}$ (탁도 $3 \mathrm{NTU}$ )을 기준으로 하였다. 


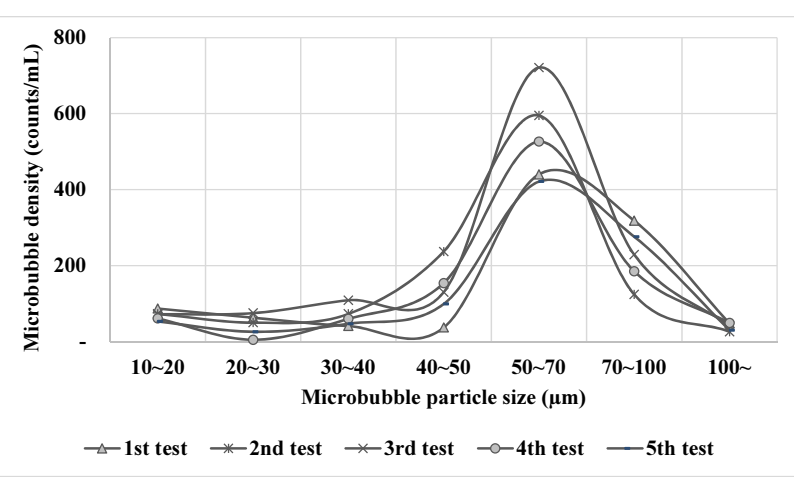

Fig. 4. Microbubble density analysis results of DAF Jar-tester.

\subsection{3. 분석기기 및 방법}

채수된 시료는 수소이온농도 $(\mathrm{pH})$, 탁도, T-P, 용존성인 $\left(\mathrm{PO}_{4}-\mathrm{P}\right)$, 화학적산소요구량(chemical oxygen demand, $\left.\mathrm{COD}\right)$ 및 $\mathrm{SS}$ 를 분석하였다. 측정에 사용한 기기로는 수온, 알칼리 도 및 $\mathrm{pH}$ 는 METTLER TOLEDO사의 Easy $\mathrm{pH}$ 와 HANNA instrument사의 HI2210 pH Meter를 사용하였으며, 탁도는 $\mathrm{HACH}$ 사의 TL2300을 사용하였다. T-P, $\mathrm{PO}_{4}-\mathrm{P}$ 및 COD의 수 질항목 측정을 위해서는 C-MAC사의 시약을 사용, $\mathrm{HACH}$ 사의 DR3900 분광광도계로 분석하였다. SS는 공정시험방법 에 의거하여 분석하였다. 전체 데이터 분석에는 Microsoft Excel과 R 프로그램을 사용하였다. SS를 통한 슬러지 분석에 있어 TSS (total suspended solids) 및 VSS (volatile suspended solids)를 측정하여 FSS (fixed suspended solids)를 산정한 뒤, FSS는 슬러지 내 무기물로 VSS는 유기성 성분으로 간 주하였다. Microbubble density는 레이저를 투사한 뒤 입자 에 의한 산란각을 측정하여 입경과 수밀도를 측정하는 LaserTrac $^{\mathrm{TM}} \mathrm{PC} 3400$ 을 이용하여 분석하였다.

\section{3. 결과 및 고찰}

\subsection{Jar-test 기반 침전부상공정모의실험 미세기포수 성상분석}

부상공정 모의실험에서 Platypus ${ }^{\circledR}$ DAF Jar-tester를 사용 하여 생성된 미세기포수의 특징을 입경대별 수밀도로 분석 하여 제시하였다(Fig.4). 입경대별 수 측정은 총 5 회 반복하 였다. 실험결과, 본 미세기포 발생장치는 $50-70 \mu \mathrm{m}$ 입경대 의 미세기포를 가장 많이 발생시키는 것으로 분석되었다. 해당 입경대의 범위는 $421-721$ 개 $/ \mathrm{mL}$ (평균 540.6 개 $/ \mathrm{mL}$ )로 분석되었다. 이를 통해 부상공정에 적합한 $100 \mu \mathrm{m}$ 이하의 기포가 가장 높은 비율로 생성됨을 확인하였고, 발생된 미 세기포수는 부상공정 모의실험의 적용에 적합함을 확인하 였다.

\subsection{Jar-test 기반 침전부상공정 모의실험 슬러지 발생특성 분석}

\subsection{1. 고형물(SS) 기준 슬러지 발생특성 분석}

침전 및 부상공정에서 발생한 슬러지의 발생특성을 분석하

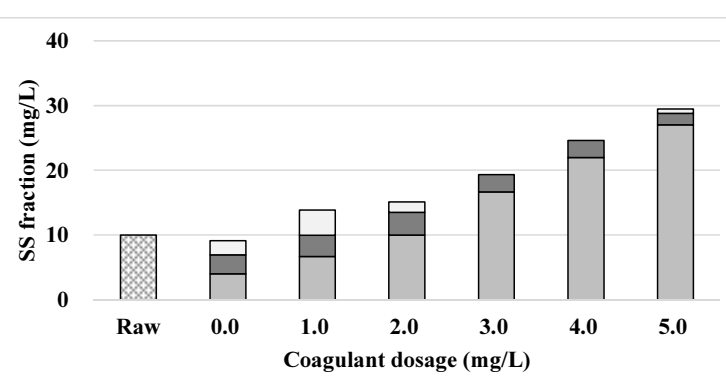

$\square$ Raw water $\square$ Sedimentation sludge $\square$ Flotation sludge $\square$ Residual

(a)

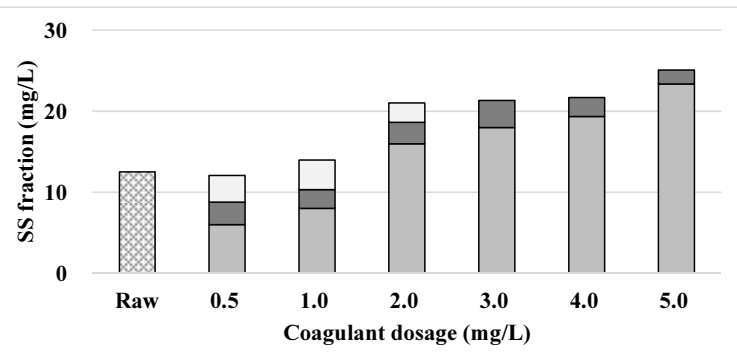

$\square$ Raw water $\square$ Sedimentation sludge $\square$ Flotation sludge $\square$ Residual

(b)

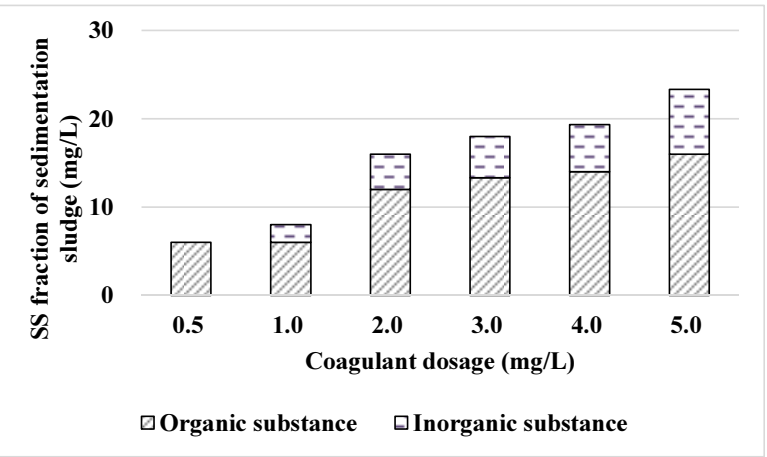

(c)

Fig. 5. SS fraction results in sludge and treated water: (a) $1^{\text {st }}$ test, (b) $2^{\text {nd }}$ test, and (c) organic and inorganic substance ratios in sedimentation sludge ( $2^{\text {nd }}$ test).

였다. 원수 SS $10 \mathrm{mg} / \mathrm{L}$ 조건(Fig.5(a), 이하 1차), $12.5 \mathrm{mg} / \mathrm{L}$ 조건(Fig.5(b), 이하 2차)일 때 응집제 주입농도에 따른 침 전슬러지(sludge after sedimentation 또는 sedimentation sludge) 및 부상슬러지(sludge after flotation 또는 flotation sludge)에 대한 SS 물질수지 분석결과를 제시하였다. 응집 제 주입농도가 증가할수록 전체 $\mathrm{SS}$ 의 총량이 증가하였다. 응집제 주입농도 $2 \mathrm{mg} / \mathrm{L}$ as $\mathrm{Al}_{2} \mathrm{O}_{3}$ 이하의 조건에서는 미처 리 상태의 SS (residual SS fraction)가 잔류하고 있으나 그 이상의 조건에서는 침전과 부상공정에서 전부 제거되었다. 전체 응집제 주입조건에 대해 부상슬러지의 농도는 일정한 비율을 유지하고 있음에 비해, 침전슬러지는 응집제 주입농 도의 증가에 따라 지속적으로 증가하였다. 응집제 주입농도 $2 \mathrm{mg} / \mathrm{L}$ as $\mathrm{Al}_{2} \mathrm{O}_{3}$ 이상의 조건에서는 발생한 총 슬러지(침전 + 부상슬러지) 내 SS 농도가 원수보다 약 $135-149 \%$ 증가 
Table 2. SS fractions according to coagulant dosage.

\begin{tabular}{|c|c|c|c|c|c|c|}
\hline \multirow{3}{*}{$\begin{array}{c}\text { C.dosage } \\
\text { (mg/L) }\end{array}$} & \multicolumn{3}{|c|}{$1^{\text {st }}$ test } & \multicolumn{3}{|c|}{$2^{\text {nd }}$ test } \\
\hline & \multicolumn{3}{|c|}{ SS fraction (mg/L) } & \multicolumn{3}{|c|}{ SS fraction (mg/L) } \\
\hline & S.sludge & F.sludge & Residual & S.sludge & F.sludge & Residual \\
\hline 0.0 & 4.0 & 3.0 & 2.1 & - & - & - \\
\hline 0.5 & - & - & - & 6.0 & 2.8 & 3.3 \\
\hline 1.0 & 6.7 & 3.3 & 3.9 & 8.0 & 2.3 & 3.7 \\
\hline 2.0 & 10.0 & 3.5 & 1.6 & 16.0 & 2.6 & 2.4 \\
\hline 3.0 & 16.7 & 2.6 & 0.0 & 18.0 & 3.3 & 0.0 \\
\hline 4.0 & 22.0 & 2.6 & 0.0 & 19.3 & 2.4 & 0.0 \\
\hline 5.0 & 27.0 & 1.8 & 0.7 & 23.3 & 1.7 & 0.0 \\
\hline
\end{tabular}

* C.dosage: coagulant dosage / S.sludge: sludge after sedimentation / F.sludge: sludge after flotation

Table 3. Sludge ratios and flotation sludge fractions for SS.

\begin{tabular}{ccccc}
\multirow{2}{*}{$\begin{array}{c}\text { Coagulant dosage } \\
(\mathrm{mg} / \mathrm{L})\end{array}$} & \multicolumn{2}{c}{ Ratio } & $1^{\text {st }}$ test & \multicolumn{2}{c}{$2^{\text {nd }}$ test } \\
\cline { 2 - 5 } & F.sludge $:$ S.sludge & F.sludge / T.sludge & F.sludge : S.sludge & F.sludge / T.sludge \\
\hline 0.0 & $1: 1.3$ & 43 & - & - \\
\hline 0.5 & - & - & $1: 2.1$ & 32 \\
\hline 1.0 & $1: 2.0$ & 33 & $1: 3.5$ & 22 \\
\hline 2.0 & $1: 2.9$ & 26 & $1: 6.2$ & 14 \\
\hline 3.0 & $1: 6.4$ & 13 & $1: 5.5$ & 15 \\
\hline 4.0 & $1: 8.5$ & 11 & $1: 8.0$ & 11 \\
\hline 5.0 & $1: 15.0$ & 6 & $1: 13.7$ & 7 \\
\hline
\end{tabular}

* F.sludge: sludge after flotation / S.sludge: sludge after sedimentation / T.sludge: total sludge

한 것으로 분석되었다.

추가로, Fig.5(c)에 2차 침전슬러지 내 무기성 및 유기성 $\mathrm{SS}$ 성분비(ratio)를 제시하였다. 실험한 응집제 주입농도의 조건에서는 유기성 성분의 함량이 무기성 성분보다 큰 것으 로 나타났다. 응집제 주입농도 $2 \mathrm{mg} / \mathrm{L}$ as $\mathrm{Al}_{2} \mathrm{O}_{3}$ 이상의 조 건에서 유기성 성분의 함량은 증가가 크지 않은데 비해, 무 기성 성분의 함량은 응집제 주입농도에 비례하여 지속적으 로 증가하는 것으로 나타났다.

이상의 응집제 주입농도에 따른 1차 및 2차 침전슬러지, 부상슬러지, 처리수 내 SS 분율(fraction)을 Table 2에 정리 하였다.

앞서 분석한 응집제 주입농도에 따라 슬러지에 포함되어 있는 $\mathrm{SS}$ 의 농도분율 분석결과에 최적처리조건(최적 응집제 주입조건)의 개념을 적용하여 Fig. 6에 도시(圖示)하였다. 주축은 SS 분율에 대하여 막대그래프로 나타내었으며, 보조 축은 응집제 주입농도에 따른 처리수질을 꺾은선그래프로 나타내었다. 최적처리조건의 응집제 주입농도는 1차 실험에 서 $2 \mathrm{mg} / \mathrm{L}$ as $\mathrm{Al}_{2} \mathrm{O}_{3}, 2$ 차 실험에서도 $2 \mathrm{mg} / \mathrm{L}$ as $\mathrm{Al}_{2} \mathrm{O}_{3}$ 로 분 석되었다.

최적처리조건에서의 슬러지 발생특성을 분석하기 위해서 응집제 주입농도별 부상슬러지 : 침전슬러지 비율(ratio) 및 부상슬러지/침전슬러지 분율(fraction)의 분석결과를 Table 3

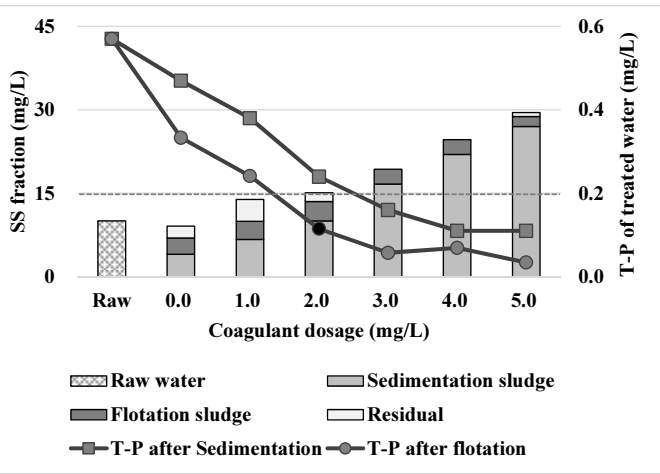

(a)

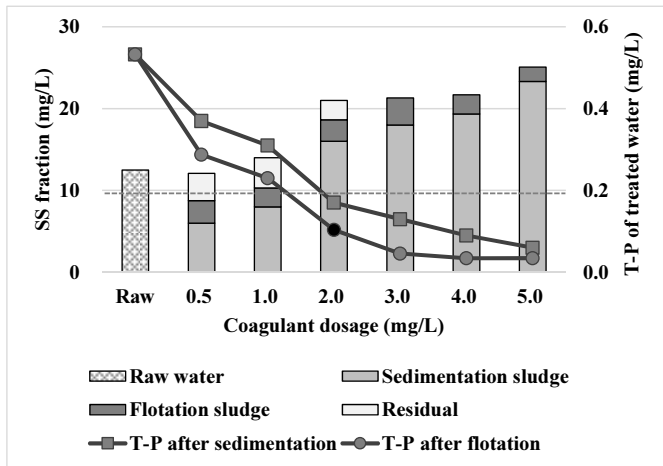

(b)

Fig. 6. SS fraction and T-P in treated water according to coagulant dosage: (a) $1^{\text {st }}$ test and (b) $2^{\text {nd }}$ test. 

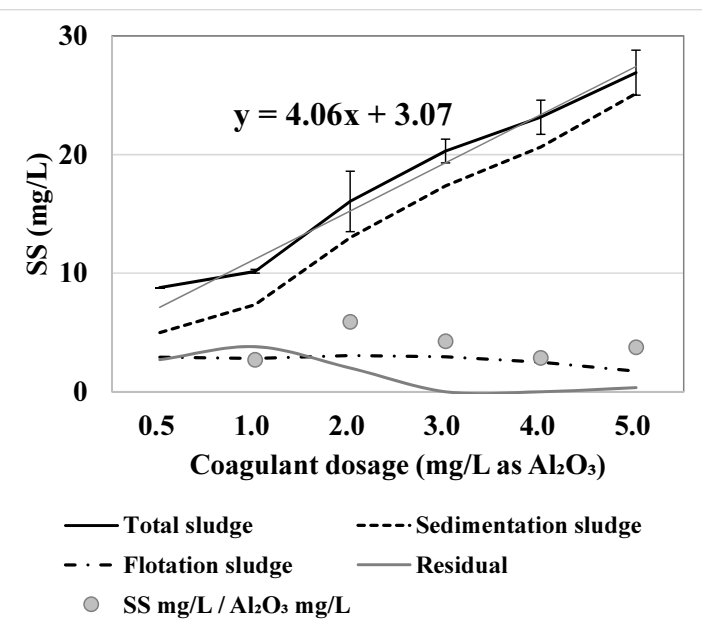

Fig.7. Increase of sludge production according to coagulant dosage $(n=11)$.

에 나타내었다. 최적처리조건에서 부상슬러지 : 침전슬러지 에 포함되어있는 SS 부하비율은 $1: 2.9$ - 1:6.2의 범위를 갖 는 것으로 분석되었다. 전체 슬러지 중 부상슬러지 내에 포 함되어있는 SS 부하분율은 $14-26 \%$ 의 범위로 나타나 SS 부하비율과 유사하게 대체로 일정한 범위의 값으로 수렴하 는 것을 확인하였다.

위의 결과를 종합하여 Fig. 7과 같이 응집제 주입농도에 따른 슬러지 내 SS 증가량을 분석하였으며, 침전슬러지와 부상슬러지를 더한 총 슬러지의 경우 응집제 주입농도의 증 가에 따라 선형적으로 증가하는 것을 확인하였다. 단순회귀 분석에 의해 도출된 값은 $4.06 \mathrm{mg} \cdot \mathrm{L}^{-1}$ as $\mathrm{SS} / \mathrm{mg} \cdot \mathrm{L}^{-1}$ as $\mathrm{Al}_{2} \mathrm{O}_{3}$ 로서, 응집제 주입농도 $\left(\mathrm{Al}_{2} \mathrm{O}_{3}\right.$ 기준 $) 1 \mathrm{mg} / \mathrm{L}$ 증가 시 약 $4 \mathrm{mg} / \mathrm{L}$ 의 슬러지(SS 기준)가 추가로 생성되는 것으로 나타났다.

\subsection{2. 총인(T-P) 기준 슬러지 발생특성 분석}

원수 T-P $0.57 \mathrm{mg} / \mathrm{L}$ 조건(Fig. 8(a), 이하 1차), $0.53 \mathrm{mg} / \mathrm{L}$ 조건(Fig.8(b), 이하 2차)일 때 응집제 주입농도에 따른 침 전슬러지 및 부상슬러지 내에 포함된 T-P 물질수지의 분석

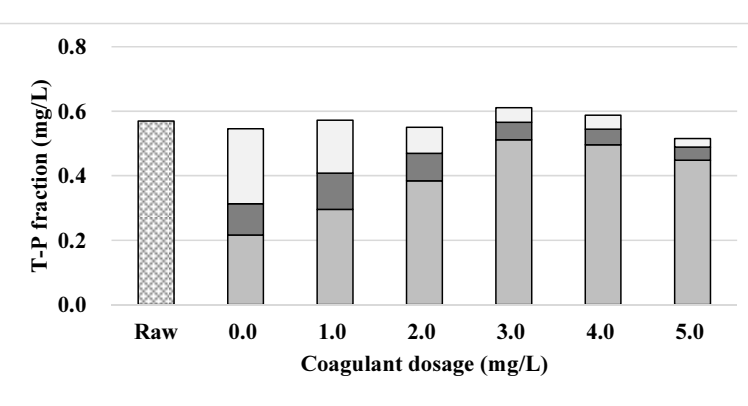

$\square$ Raw water $\square$ Sedimentation sludge $\square$ Flotation sludge $\square$ Residual

(a)

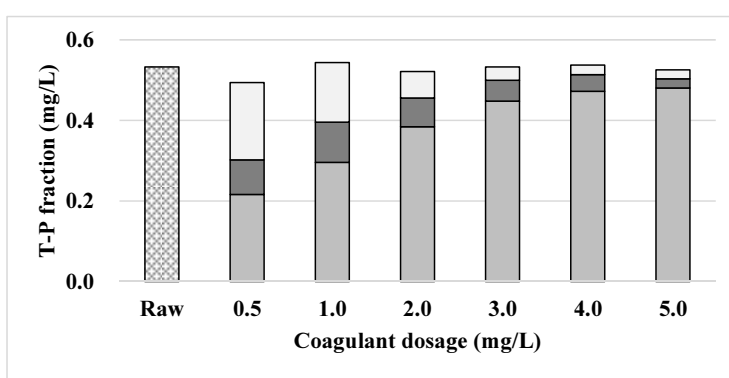

๑Raw water $\square$ Sedimentation sludge $\square$ Flotation sludge $\square$ Residual

(b)

Fig. 8. T-P fraction results in sludge and treated water: (a) $1^{\text {st }}$ test and (b) $2^{\text {nd }}$ test.

결과를 제시하였다. 응집제 주입농도의 증가와 관계없이 전 체 T-P의 총 농도는 일정하되 분율만 변하는 것으로 관찰되 었다.

침전슬러지 내 T-P 분율은 응집제 주입농도가 증가할수록 점차 증가하여 원수농도(총 농도)에 가깝게 수렴하는 것을 확인하였으며, 부상슬러지 내 T-P 분율은 일정한 농도를 유 지하다가 최적처리조건 이후 점차 감소하였다(Table 4).

최적처리조건에서의 응집제 주입농도는 $\mathrm{SS}$ 와 동일하게 1차 및 2차 실험에서 모두 $2 \mathrm{mg} / \mathrm{L}$ 로 분석되었다(Fig. 9).

최적처리조건에서의 부상슬러지 : 침전슬러지에 포함되어 있는 T-P 부하비율(ratio)은 $1: 4.2-1: 5.4$ 의 범위를 갖는 것 으로 분석되었으며, 전체 슬러지 중 부상슬러지 내에 포함

Table 4. T-P fractions according to coagulant dosage.

\begin{tabular}{|c|c|c|c|c|c|c|}
\hline \multirow{3}{*}{$\begin{array}{c}\text { C.dosage } \\
\text { (mg/L) }\end{array}$} & \multicolumn{3}{|c|}{$1^{\text {st }}$ test } & \multicolumn{3}{|c|}{$2^{\text {nd }}$ test } \\
\hline & \multicolumn{3}{|c|}{ T-P fraction (mg/L) } & \multicolumn{3}{|c|}{ T-P fraction (mg/L) } \\
\hline & S.sludge & F.sludge & Residual & S.sludge & F.sludge & Residua \\
\hline 0.0 & 0.22 & 0.10 & 0.23 & - & - & - \\
\hline 0.5 & - & - & - & 0.22 & 0.09 & 0.19 \\
\hline 1.0 & 0.30 & 0.11 & 0.16 & 0.30 & 0.10 & 0.15 \\
\hline 2.0 & 0.38 & 0.09 & 0.08 & 0.38 & 0.07 & 0.07 \\
\hline 3.0 & 0.51 & 0.05 & 0.04 & 0.45 & 0.05 & 0.03 \\
\hline 4.0 & 0.50 & 0.05 & 0.04 & 0.47 & 0.04 & 0.02 \\
\hline 5.0 & 0.45 & 0.04 & 0.03 & 0.48 & 0.02 & 0.02 \\
\hline
\end{tabular}

* C.dosage: coagulant dosage / S.sludge: sludge after sedimentation / F.sludge: sludge after flotation 


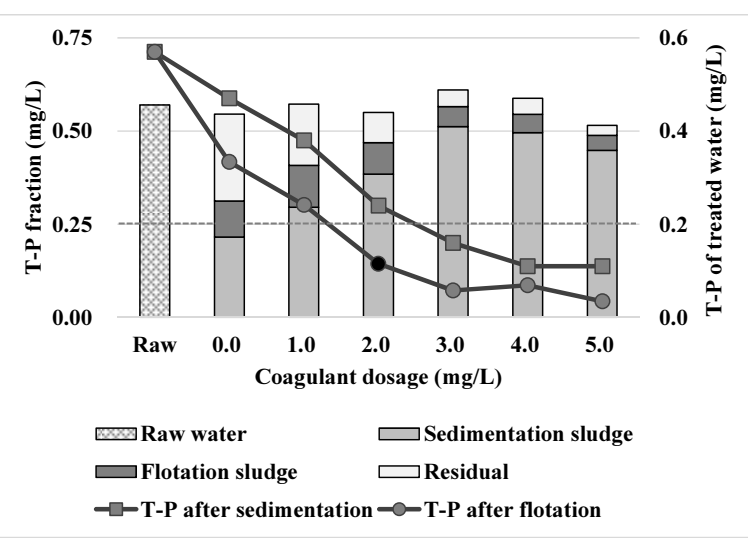

(a)

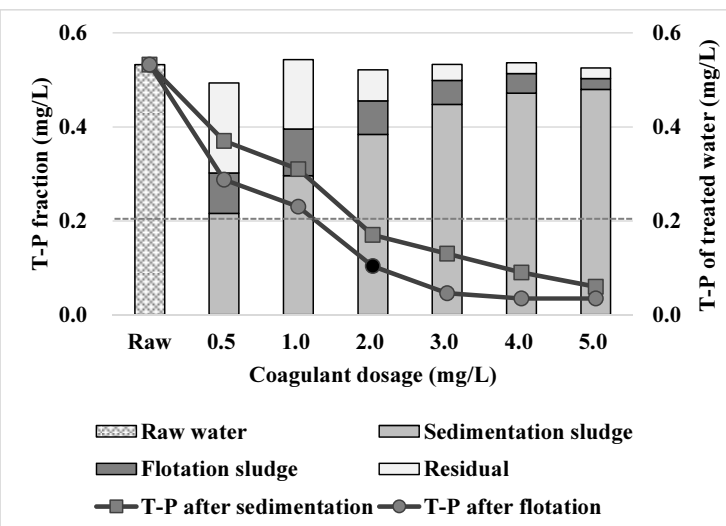

(b)

Fig. 9. T-P fraction and T-P in treated water according to coagulant dosage: (a) $1^{\text {st }}$ test and (b) $2^{\text {nd }}$ test.

되어 있는 T-P 부하분율(fraction)은 $16-19 \%$ 의 범위로 나타 나 두 지표 모두 일정한 범위의 값으로 수렴하는 것을 확인 하였다(Table 5).

\section{3. 슬러지 발생특성을 고려한 침전부상공정의 운전 적정성 \\ 모니터링 지표 도출}

이상에서 논의한 내용을 개념도로 정리하면 Fig. 10과 같 다. 침전 및 부상 슬러지 내의 수질인자(SS 및 T-P 기준)의

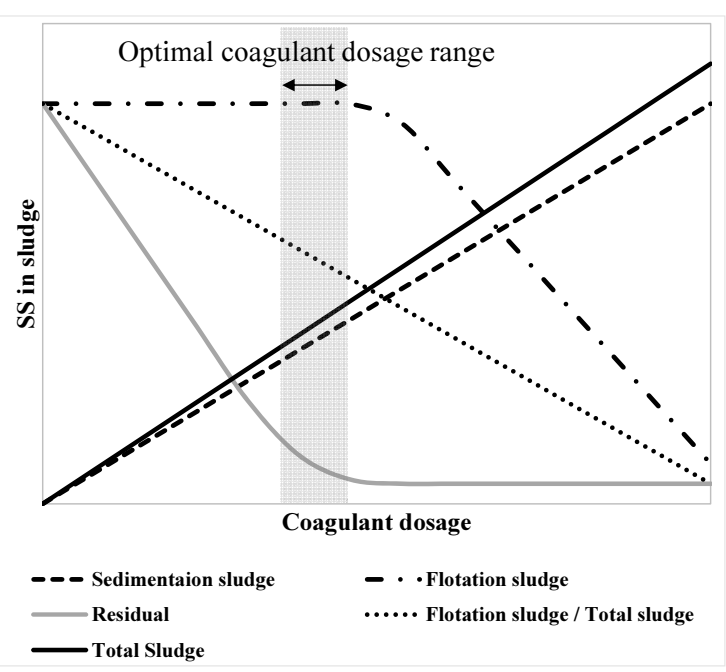

(a)

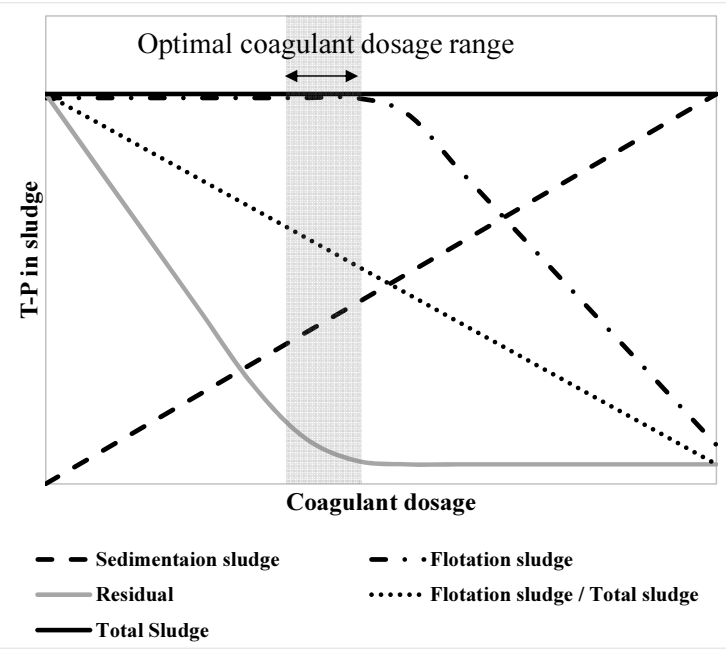

(b)

Fig. 10. Concept of monitoring indices for sludge production characteristics according to coagulant dosage: (a) SS and (b) T-P.

부하비율 및 분율은 최적처리조건에서 일정한 범위를 갖게 되며, 현장운전 시 해당 인자를 모니터링할 경우 운전의 적

Table 5. Sludge ratios and flotation sludge fractions for T-P.

\begin{tabular}{|c|c|c|c|c|}
\hline \multirow{3}{*}{$\begin{array}{l}\text { Coagulant dosage } \\
(\mathrm{mg} / \mathrm{L})\end{array}$} & \multicolumn{2}{|c|}{$1^{\text {st }}$ test } & \multicolumn{2}{|c|}{$2^{\text {nd }}$ test } \\
\hline & Ratio & Fraction (\%) & Ratio & Fraction (\%) \\
\hline & F.sludge : S.sludge & F.sludge / T.sludge & F.sludge : S.sludge & F.sludge / T.sludge \\
\hline 0.0 & $1: 2.2$ & 31 & - & - \\
\hline 0.5 & - & - & $1: 2.4$ & 29 \\
\hline 1.0 & $1: 2.7$ & 27 & $1: 3.0$ & 25 \\
\hline 2.0 & $1: 4.2$ & 19 & $1: 5.4$ & 16 \\
\hline 3.0 & $1: 10.2$ & 9 & $1: 9.0$ & 10 \\
\hline 4.0 & $1: 10.0$ & 9 & $1: 11.8$ & 8 \\
\hline 5.0 & $1: 11.3$ & 8 & $1: 24.0$ & 4 \\
\hline
\end{tabular}

* F.sludge: sludge after flotation / S.sludge: sludge after sedimentation / T.sludge: total sludge 
정성을 판단할 수 있는 하나의 지표로 사용할 수 있을 것으 로 사료된다. 특히, 최적처리조건을 전후하여 부상공정에 의해 제거된 슬러지 중의 SS 및 T-P (flotation sludge) 분율 이 급감하며, 미처리 SS 및 T-P (residual SS and T-P)가 최 소화되는 공통된 특징을 갖는 것으로 나타났다.

\section{4. 결 론}

본 연구에서는 기존의 인 고도처리공정의 단점을 보완한 새로운 공정으로 일체형 침전부상공정( $\mathrm{SeDAF}$ process)을 개발하였으며 ${ }^{13-16)}, \mathrm{SeDAF}$ 공정의 운전특성을 파악하기 위 하여 수정된 Jar-test 기법을 기반으로 하여 침전과 부상의 각 단위공정을 모사한 실험실 규모 연구를 수행하였다. 여 러 실험분석을 통하여 최적처리조건에서의 수질적 운전특 성 및 슬러지 발생특성을 집중적으로 규명한 본 연구의 결 론은 다음과 같다.

1) 같은 농도의 응집제를 주입한 경우를 서로 비교한 결 과, 침전공정 대비 $\mathrm{SeDAF}$ 공정에서 더 개선된 $\mathrm{SS}$ 및 $\mathrm{T}-\mathrm{P}$ 의 처리수질과 제거효율의 안정성이 확인되었다.

2) Poly Aluminium Chloride ( $\mathrm{PAC}, \mathrm{Al}_{2} \mathrm{O}_{3} 10 \%$, 염기도 $40 \%$ )를 응집제로 사용한 본 실험조건에서 $\mathrm{SeDAF}$ 공정의 슬러지 발생량은 $4 \mathrm{mg} \cdot \mathrm{L}^{-1}$ as $\mathrm{SS} / \mathrm{mg} \cdot \mathrm{L}^{-1}$ as $\mathrm{Al}_{2} \mathrm{O}_{3}$ 의 비율 을 갖는 것으로 분석되었다. 응집제 사용량에 따라 슬러지 발생량 또한 선형적으로 비례하여 증가하는 것으로 나타나, 응집제 주입농도의 저감이 슬러지 발생량의 감소에 직접적 으로 기여할 것으로 판단된다.

3) $\mathrm{SeDAF}$ 공정의 최적처리조건(최적 응집제 주입조건)에 서 부상슬러지 및 침전슬러지에 각각 포함되어있는 수질인 자 부하비율(ratio)을 분석한 결과, 일정한 범위로 수렴하는 경향성이 관찰되었으며 SS는 $1: 2.9$ - 6.2, T-P는 $1: 4.2$ - 5.4 의 범위를 갖는 것으로 나타났다.

4) $\mathrm{SeDAF}$ 공정의 최적처리조건에서 전체 슬러지 중 부상 슬러지 내에 포함되어 있는 수질인자의 부하분율(fraction) 을 분석한 결과, 일정한 범위로 수렴하는 경향성이 관찰되 었으며 SS는 $14-26 \%$, T-P는 $16-19 \%$ 범위를 갖는 것으로 나타났다.

5) $\mathrm{SeDAF}$ 공정의 현장 운영 시에는 최종처리수의 목표수 질을 달성하는 것뿐만 아니라 슬러지 내 수질인자(SS 및 T-P)의 부하비율(ratio) 및 부하분율(fraction)을 일정한 범위 내로 유지함으로써 적정한 운전이 가능할 것으로 판단된다.

\section{Acknowledgement}

본 연구는 한국건설기술연구원 주요사업의 연구비 지원 으로 수행되었습니다(과제번호: 20200039-001). 이에 감사 드립니다.

\section{References}

1. Ministry of Environment, Korean Design Standards of Sewage Facility, Ministry of Environment, Sejong, Korea, pp. 1-107(2019).

2. Metcalf \& Eddy, Inc., Wastewater Engineering, 5th ed., McGraw-Hill Education, USA, pp. 1-1942(2016).

3. W. C. Park, M. A. Lee, I. W. Sung, Phosphorus removal from advanced wastewater treatment process using PAC, J. Korean Soc. Environ. Eng., 36(2), 96-102(2014).

4. J. P. Malley Jr., J. K. Edzwald, Laboratory comparison of DAF with conventional treatment, J.-Am. Water Works Assoc., 83(9), 56-61(1991).

5. Gyeonggi Research Institute, Method for Efficient Treatment of Sewage Sludge(2018).

6. C. J. Cheong, Removal of microalgae using inorganic coagulants in coagulation and sedimentation processes for water treatment, J. Korean Soc. Environ. Eng., 30(1), 85-89 (2008).

7. J. K. Edzwald, D. Q. Bunker, J. Dahlquist, L. Gillberg, T. Hedberg, Dissolved air flotation: pretreatment and comparisons to sedimentation, Chemical Water and Wastewater Treatment III, R. Klute, H. H. Hahn (eds), Springer, Berlin, Germany, pp. 3-18(1994).

8. K. C. Lee, Characteristics of phosphorus removal in treated sewage using microbubble flotation system, Ph.D. thesis, University of Seoul(2011).

9. L. K. Wang, N. K. Shammas, W. A. Selke, D. B. Aulenbach, Flotation Technology, Humana Press, Totowa, USA, pp. 1-665(2010).

10. Ministry of Environment, A Study on Improvement Methods for Treatment Efficiency of Phosphorus Treatment Facilities, Ministry of Environment, Sejong, Korea, pp. 1-183(2012).

11. Y. J. Jang, J. H. Jung, H. M. Lim, W. J. Kim, Applicability of integrated SeDAF (Sedimentation. Dissolved air flotation) process for advanced wastewater treatment, in Proceedings of KSWW · KSWE, KSWW - KSWE, pp. 451-452(2019).

12. S. J. Kim, S. M. Park, H. Y. Park, K. C. Lee, O. S. Kwon, Best Available Technology and Management Practice using Physicochemical Methods for Phosphorus Removal in Municipal Wastewater Treatment Plants in the Priority Areas of 4 Major Rivers, National Institute of Environmental Research, Incheon, Korea, pp. 1-23(2010).

13. Y. J. Jang, J. H. Jung, H. Y. Chang, N. R. Park, H. M. Lim, W. J. Kim, Decision of optimal coagulant dosage for SeDAF (sedimentation and dissolved air flotation) process applicable to enhanced phosphorus removal, KSWST Jour. Wat. Treat., 28(4), 33-42(2020).

14. Y. J. Jang, J. H. Jung, K. H. Ahn, H. M. Lim, W. J. Kim, Applicability of $\mathrm{Al} / \mathrm{P}$ (aluminium/phosphorus) ratio in SeDAF process for enhanced phosphorus removal, J. Korean Soc. Environ. Eng., 42(11), 539-547(2020).

15. Y. J. Jang, J. H. Jung, H. M. Lim, W. J. Kim, Empirical evaluation for design parameters and operating characteristics of the integrated sedimentation and flotation process at the 
pilot-scale plant, J. KSWW, (In press)(2020).

16. Y. J. Jang, J. H. Jung, W. J. Kim, Automatic control of coagulant dosage on the sedimentation and dissolved air flotation (SeDAF) process for enhanced phosphorus removal in sewage treatment facilities, J. KSWW, (In press)(2020).

17. Korea Ministry of Government Legislation, http://www.law.go.kr, $\operatorname{May}(2020)$.

18. H. Y. Park, S. M. Park, K. C. Lee, S. J. Yu, O. S. Kwon, S. J. Kim, Survey of physicochemical methods and economic analysis of domestic wastewater treatment plant for advanced treatment of phosphorus removal, J. Korean Soc. Environ. Eng., 33(3), 212-221(2011).

\section{Authors}

\section{Yeoju Jang}

University of Science and Technology (UST, KICT School), Civil \& Environmental Engineering, Master of Engineering, ORCID(1) 0000-0001-5858-5548

\section{Jinhong Jung}

Korea Institute of Civil Engineering and Building Technology (KICT), Department of Land, Water and Environment Research, Environmental Resource Research Center, Ph.D., ORCID(D) 0000-0002-9698-597X

\section{Hyangyoun Chang}

University of Science and Technology (UST, KICT School), Civil \& Environmental Engineering, Ph.D. Candidate, ORCID (D) 0000-0002-6808-6985

\section{Nari Park}

University of Science and Technology (UST, KICT School), Civil \& Environmental Engineering, Ph.D. Candidate, ORCiD(D) 0000-0003-3297-6203

\section{Miratul Maghfiroh}

University of Science and Technology (UST, KICT School), Civil \& Environmental Engineering, Ph.D. Candidate, ORCiD(0) 0000-0001-6030-6675

\section{Weonjae Kim}

Korea Institute of Civil Engineering and Building Technology (KICT), Department of Land, Water and Environment Research, Environmental Resource Research Center, Ph.D. \& Professor, ORCID(10) 0000-0001-5676-5131 